\title{
MICROSTRUCTURE ANALYSIS OF GENUINE COPPER ALLOY COIN
}

\section{EDIE SASITO SARWODIDOYO}

Department Refrigeration and Airconditiong, Politehnik Negeri Bandung. Indonesia

\begin{abstract}
Coin characterization analysis (coins) is done by using the test method such as; Spectrometer XRF, XRD Defractometer, Deferential Scanning Calorimeter, Scanning Electron Microscope (SEM). Characterization is done in Lab Material Sciences Salemba UI to reveal the nature of coin properties related to mass density, coin base material, particle size of material, heat capacity properties. Qualitatively coins must have public security factors without having to reduce the function and security of the coin itself. The function of characterization testing is to see the superiority of coin material as a means of exchange of trade transactions, so that the coin is resistant to impact of scratches, resistant to corrosion when stored in the long term. In the physical configuration test, the coin dimension (diameter $27 m m, 2 m m$ thick) average coin mass of 7.48 gram / cc. The microstructure test with XRF element in coins is Cu, Ni, Al, P, Mn, Si. XRD test coin is an alloy Cu0.9Ni0.1 degan ring aluminum oxide. AlxOy Hardness CuNi $84.56 \mathrm{HV}$ alloys, and AlxOy 72.55HV SEM test brass alloys show more than 2 kinds of micro grain figure material with almost the same grain size, while the aluminum compound has a grain figure of more than 2 kinds with different sizes.
\end{abstract}

KEYWORDS: Coins, Metal Alloys, Figure \& DSC

Received: Nov 24, 2017; Accepted: Dec 14, 2017; Published: Jan 06, 2018; Paper Id.: IJMMSEFEB20181

\section{INTRODUCTION}

Coins (coins) 1000 IDR is a tool of transactions applicable in Indonesia, which must have the nature of physical properties, among others; strong and corrosion resistant so that the form has not changed in the long term, relatively light and non-toxic. Crystal structure is one that determines the physical properties of materials. To meet some requirements of the properties of fika that must be dimilika materials, then the material of which is made of composite this is a mixture of some materials (alloys) and ceramics. To find out the above requirements, it is necessary to test XRF, XRD, electrical resistifitas, and conductivity of heat materials. The basic ingredients of the coins are closely included in the State's secret categories, not everyone may know except those designated by the State and for the benefit of education and science.

Simply scientists can guess that the basic ingredients of coins must not be pure metal, or ceramics. Given the two basic materials do not meet all the requirements required for the coin. Among others; strong, not easily peyok and scratched, rustproof, heat resistant, and not corroded so that the nominal value of money is still listed in the long term, lightweight, and economical, the value of coin is much cheaper than the value of transaction convention coins. One of the materials that meet the kretteria is a material of metal alloy (Alloy). 


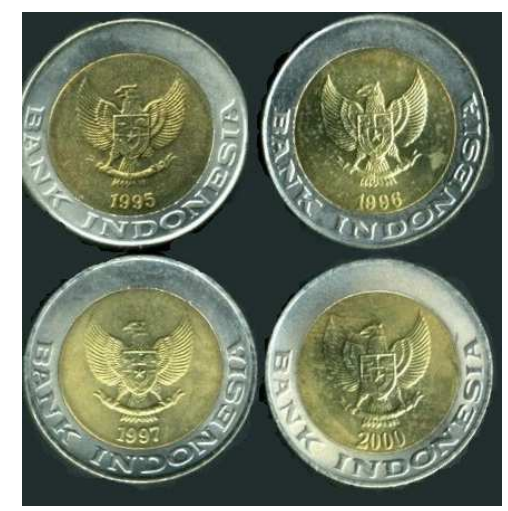

Figure 1: Metal Coins Picture 1000 IDR Thn.2000

Coins 1000 IDR, has 2 kinds of macro material, which is golden yellow brass material in the center position of diameter $19 \mathrm{~mm}$, thickness $2 \mathrm{~mm}$ and, while the aluminum material is on the ring (ring) with outside diameter outside diameter $27 \mathrm{~mm}$ with a thickness of flat average $2 \mathrm{~mm}$. the mass of 8.57 grams of coins with an average weight of $\rho=7.48$ (gram / cc).

Each material of alloy has properties depending on the composition and the material to be integrated, then the microstructure analysis using X-ray diffraction method and XRF spectrometer provides an advantage other than being able to know the type of material but also able to determine the crystal structure, thus can be predicted the nature of the macro properties of the material will be the subject of study. For example, if the desired material has a high hardness it is necessary to select the material with a hcp crystal structure (hexagonal Close Packed) or fcc (face center cube) structure. And vice versa if found hcp or fcc structure can be expected material has high level of hardness. For the physical properties that cannot be determined by X-ray method, thermal test methods such as DTA and DSC (Deferential Scanning Calorimeter) are used i.e. a thermal test method to determine the heat capacity and thermal conductivity of the material. The heat capacity $(\mathrm{Cp})$ and thermal conductivity $(\kappa)$ of material need to be known to determine in addition to the properties of the insulator and the conductor, but also to predict the crystallinity properties of the material. The crystalline material generally has a higher $\kappa$ constant than the non crystalline (amorphous) materialal.

\section{THE OBJECTIVES OF CHARACTERIZATION CHARACTER PRINCIPLES}

The purpose of the practice is; (1) determining the type of 1000 ID coin metal using the X-ray test method, and (2) determining the nature of the macro and thermal properties in relation to the microstructure already obtained.

\section{II.1 Practice Method}

Place of Practice. Practice of coin characterization is done in Material Laboratory, Material Science Study Program, Graduate University of Indonesia, Jakarta, from October to December 2010.

\section{II.2 Practice Materials}

The test material is a coin (coin) with a nominal value of Rp 1000, -, the year of use around 1996.

\section{II.3 The Practice Tool}

There is a set of test equipment, among others; (1) a set of XRF spectrometer test kits, (2) a set of XRD defractometer test kits, (3) a set of DSC thermo gram test kits, (4) a set of SEM measuring instruments, (5) a set of 
hardness tools, (6) a set a simple calorimeter gauge and (7) a set of preliminary test kits.

\section{II.4 Training Priority Test}

With respect to characterization traits there is a destructive sample and some do not damage the sample, then the priority of testing prioritizes non-destructive test samples, e.g. (1) preliminary test (geometry and mass density of the sample),

(2) XRF test to determine the element elements constructing the sample material,

(3) XRD test to determine the crystal properties of the material.

Further tests are damaging to the sample, among others; (1) DSC test to determine the thermal properties of the sample, (2) SEM test to determine the grain size of the sample element. (3) Hardness test, to determine the hardness of the sample.

\section{II.5 Sample Testing}

\section{Preliminary Test}

a. Determination of coin dimension using the sliding term to determine coin volume, obtained coin diameter $=27$ $\mathrm{mm}$, coin thickness $=2 \mathrm{~mm}$, so the volume of coin $=$

b. Volume of brass alloy parts. Darkness $=19 \mathrm{~mm}, 2 \mathrm{~mm}$ thick

c. Determination of sample weight using digital analytical scale, obtained by weight of coin $\mathrm{m}=8.57$ gram . Given the density of the coin $\rho=7.48[\mathrm{~kg} /$ liter $]=7.48[\mathrm{~g} / \mathrm{cc}]$

\section{XRF Spectrometer Test}

The atomic content of the coin-forming agent expressed in $\mathrm{wt}^{2} \%$, is; $\mathrm{Al}=5.89 \mathrm{Si}=0.44 \mathrm{P}=1.42 \mathrm{Mn}=0.08 \mathrm{Ni}=$ $1.46 \mathrm{Cu}=90.70$

\section{XRD Defractometer Test}

Using a set of X-ray defraction instruments in Lab Material, Salemba UI campus, Phillip Brand

The angles of the two emerging theta are $52^{\circ}, 59^{\circ}$, and $88^{\circ}$

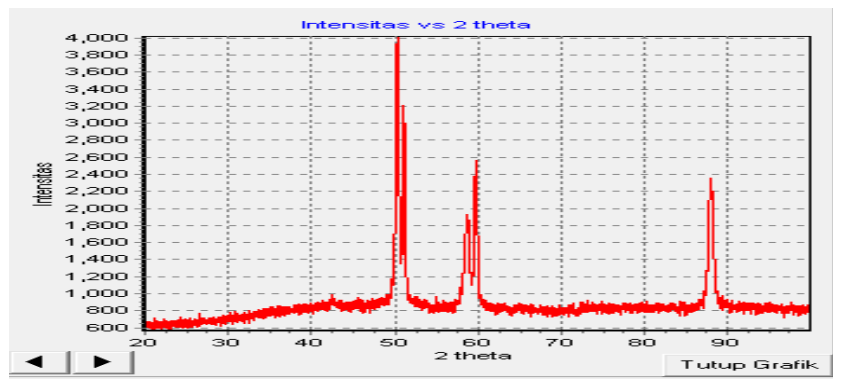

Figure 2: GSAS Rietveld Refinement of X-Ray Coin IDR 1000 Year 2000 


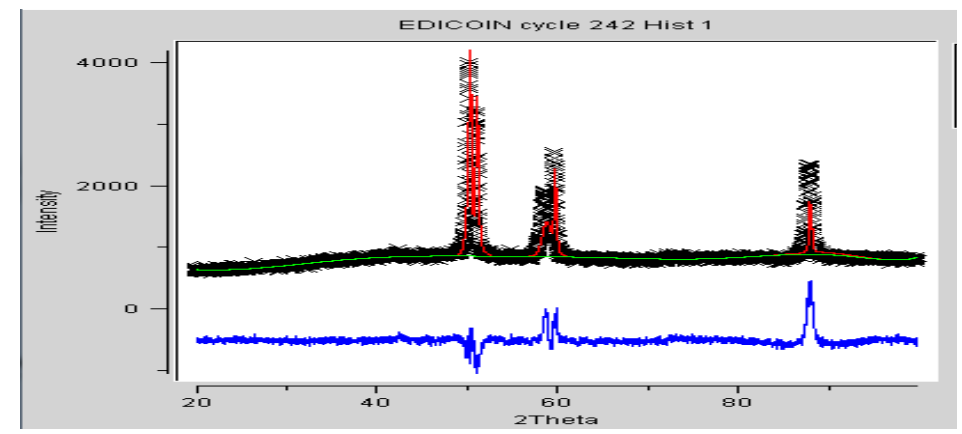

Figure 3: X-Ray Pattern of Coin IDR 1000, Year 2000

3. b Extraction from the Expg UI GSAS program, the two data Theta processed with EXCELL

To determine lattice parameters and atom fingers as follows

\begin{tabular}{|c|c|c|c|c|c|c|c|c|c|c|c|c|}
\hline \multirow[t]{2}{*}{ No } & \multicolumn{2}{|c|}{ SUDUT 2THETA } & \multirow{2}{*}{$\begin{array}{c}\sin (\theta) \\
{[\theta \mathrm{dlm} \mathrm{rad}]}\end{array}$} & \multirow[t]{2}{*}{$\operatorname{Sin}^{2}(\theta)$} & \multirow{2}{*}{$\mid \begin{array}{l}\sin ^{2}(\theta n) / \\
\sin ^{2}(\theta n-1)\end{array}$} & \multirow{2}{*}{$\begin{array}{l}3 X \operatorname{Sin}^{2}(\theta n) / \\
\operatorname{Sin}^{2}(\theta n-1)\end{array}$} & \multirow[t]{2}{*}{$h^{2}+k^{2}+L^{2}$} & \multirow[t]{2}{*}{$d h k l$} & \multirow{2}{*}{$\begin{array}{l}\text { Struktur } \\
\text { Kristal }\end{array}$} & \multirow{2}{*}{$\begin{array}{l}\text { Estimasi } \\
\text { kisi a }\end{array}$} & \multirow{2}{*}{$\begin{array}{l}\text { Jari jari } \\
\text { atom }\end{array}$} & \multirow{2}{*}{$\begin{array}{l}\text { Estmasi } \\
\text { Unsur }\end{array}$} \\
\hline & (28) & $(\theta)$ & & & & & & & & & & \\
\hline 1 & 50 & 25 & 0,42241777 & 0,04679938 & 3,65563 & 10,9668901 & 4 & $200,002,020$ & FCC & 3,6468636 & 1,2894 & $\mathrm{Cu}$ \\
\hline 2 & 59 & 29,5 & 0,49219636 & 0,0647579 & 5,058421 & 15,1752619 & 5 & $210,102,021$ & FCC & 3,4992769 & 1,2372 & $\mathrm{Ni}$ \\
\hline 3 & 88 & 44 & 0,09437827 & 0,14019491 & 10,95102 & 32,8530479 & 11 & $311,113,131$ & $\mathrm{FCC}$ & 3,6790181 & 1,3007 & Rh \\
\hline
\end{tabular}

\section{Hardness Test (Hardness)}

Hardness is a measure of the resistance of coins to localized plastic deformations (small bends or scratches). There are several methods of violence testing, among others:

- $\quad$ Rockwell hardness test

- Brinell hardness test

- Violent vicker test

- Kwoop violence test

For the purpose of verification of microstructure test, vicker hardness test and kwoop hardness test are used. Knoop and Vickers Micro hardness tests

\section{Indeter: pyramid Diamond LOAD}

$1-1000 \mathrm{gr}$

The results of the test in the curve examined with a microscope.

$\mathrm{HK}=$ hardness number knoop (KHN) HV = hardness number vickers (VHN) Knoop and Vickers are used for micro hardness testing

The coin hardness test results stated in HV is

\section{SEM Test, to See Graininess, Grain Size, and Material Impurities}

The Electron Microscope Scanning Test is performed to ensure phase diversity, phase size (grain size), phase configuration in materials. In the SEM test the sample is polished smoothly and placed in a certain size mounting. 
The transducer obtains an image signal from the metal surface, subsequently conditioned into a digital signal, and forwarded to the data processing card. Processed data is processed further using personal computer (PC) by using image processing software obtained images in JPG, as in the picture taken.

SEM image of coin surface structure 1000 IDR

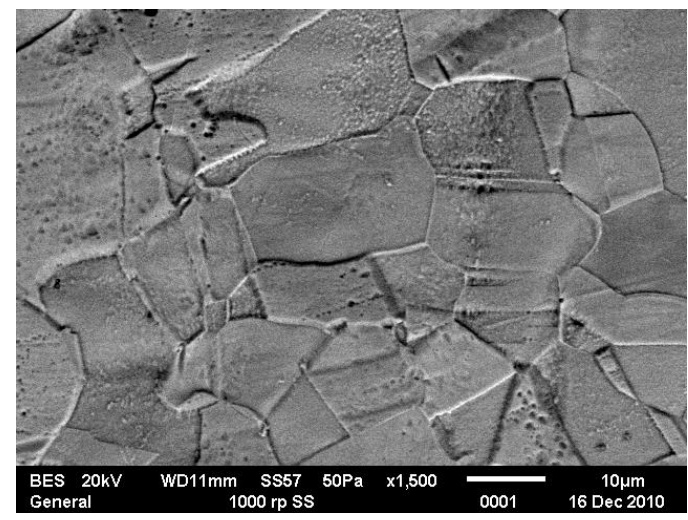

Figure 4: SEM Image Structure of IDR 1000 Coin

The image shows that in the SEM alloy CuNi results, there are several elements, i.e. two models of elements larger than $10 \mathrm{um}$, there are 2 figures, smaller than $10 \mathrm{um}$ there are more than 3 figures, meaning that there are more than 2 elements in the alloy. The elements of the element are impeded as an outer element (impurities) such as $\mathrm{Si}, \mathrm{P}$, and $\mathrm{Mn}$. In the SEM results of the outer coin material (the ring portion, there is only one type of elemental figure larger than $10 \mu \mathrm{m}$.), the element is thought to be an Aluminum oxide compound. 6 Thermal Tests of Coin Samples by DSC Method were done. Identification of DSC Thermo grams in heat capacity investigation reveals: 1. Described on the diagram area with a striking temperature change pattern, but with an insignificant power change pattern. This is done considering the heating with relative constant temperature energy is used for phase change. 2. At the transition boundary is the peak where, the mixed phase begins to interrupt which may begin to form a new phase core nucleus. 3. At each peak is informed the initial temperature and the final temperature through the peak (onset and end set) and heat energy expressed in [joule] or [k. joule /g]. With the heat energy equation.

$$
\begin{aligned}
& Q=m x C_{p} x \Delta t, \quad Q /\left.m\right|_{x}=C_{p} x \Delta t_{x}=H_{m x} \\
& Q /\left.m\right|_{y}=C_{p} x \Delta t_{y}=H_{m y} \text { Top of Form } \\
& C_{p x}=\frac{H_{m x}}{t_{x}} ; \quad C_{p y}=\frac{H_{m y}}{t_{y}}
\end{aligned}
$$

$\mathrm{Q} / \mathrm{m}$ denote specific calorific energy, then $\Delta \mathrm{Q} / \mathrm{m}$ denotes a specific heat difference. From the above equation, we get the capacity of heat at a certain temperature. The heat capacity of the material is generally expressed by the equation

$$
\begin{aligned}
& C_{p}=a+b T+c T^{2} \\
& \frac{d C_{p}}{d T}=b+c T
\end{aligned}
$$


$\frac{d C_{p 1}}{d T_{1}}=b+2 c T_{1}$, with $C_{p 1}=\frac{H_{m 1}}{T_{1}}, \frac{d C_{p 1}}{d T_{1}}=\frac{-H_{m 1}}{T_{1}^{2}}$

$\frac{d C_{p 2}}{d T_{2}}=b+2 c T_{2}, w i t h C_{p 2}=\frac{H_{m 2}}{T_{2}}, \frac{d C_{p 2}}{d T_{2}}=\frac{-H_{m 2}}{T_{2}^{2}} \quad$ Obtained $\frac{H_{m 2}}{T_{2}^{2}}-\frac{H_{m 1}}{T_{1}^{2}}=2 c\left(T_{1}-T_{2}\right)$

so as to obtain the coefficients $\mathrm{a}, \mathrm{b}$ and $\mathrm{c}$ as follows;

$$
\begin{aligned}
& c=\frac{1}{2}\left\{\frac{H_{m 2}}{T_{2}^{2}}-\frac{H_{m 1}}{T_{1}^{2}}\right\}\left\{\frac{1}{\left(T_{1}-T_{2}\right)}\right\} \\
& b=\frac{\left\{\left(C_{p 1}-C_{p 2}\right)-c\left(T_{1}^{2}-T_{2}^{2}\right)\right\}}{\left(T_{1}-T_{2}\right)} \\
& a=C p_{1}-b T_{1}-c T_{1}^{2}
\end{aligned}
$$

The DSC thermogram is obtained as follows;

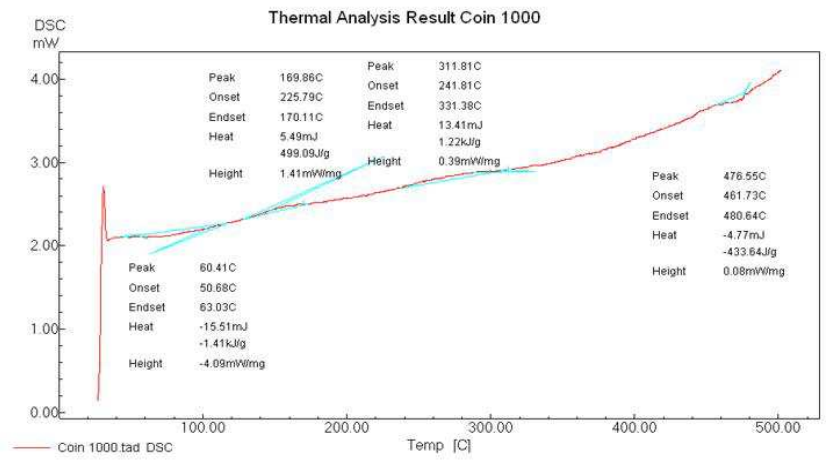

Figure 5: DSC Graph of IDR 1000 Coin

\section{Table of Specific Thermal Conditions Test Sample}

\begin{tabular}{|l|c|c|c|}
\hline $\begin{array}{c}\text { Keadaan } \\
\text { Termal }\end{array}$ & $\begin{array}{c}\text { Daya } \\
{[\mathbf{m W}]}\end{array}$ & $\begin{array}{c}\text { Range } \\
\text { Suhu }\end{array}$ & Suhu \\
\hline $\begin{array}{c}\text { Adiabatik 1 } \\
\mathrm{H}_{01}\end{array}$ & 2.10 & $65^{\circ}-75^{\circ}$ & \\
\hline $\begin{array}{c}\text { Adiabatik 2 } \\
\mathrm{H}_{02}\end{array}$ & 2.90 & $290^{0}-310^{0}$ & \\
\hline $\begin{array}{l}\text { Adiabatik 3 } \\
\mathrm{H}_{03}\end{array}$ & 3.70 & $480^{0}-490^{\circ}$ & \\
\hline $\begin{array}{l}\text { Peak 1 } \\
\mathrm{H}_{\mathrm{x} 1}\end{array}$ & -1410 & & $60.41^{0}$ \\
\hline $\begin{array}{l}\text { Peak 2 } \\
\mathrm{H}_{\mathrm{x} 2}\end{array}$ & -1220 & & $311.8^{0}$ \\
\hline
\end{tabular}

Coin Heating Capacity Table 1000 IDR Termogram Based DSC. 


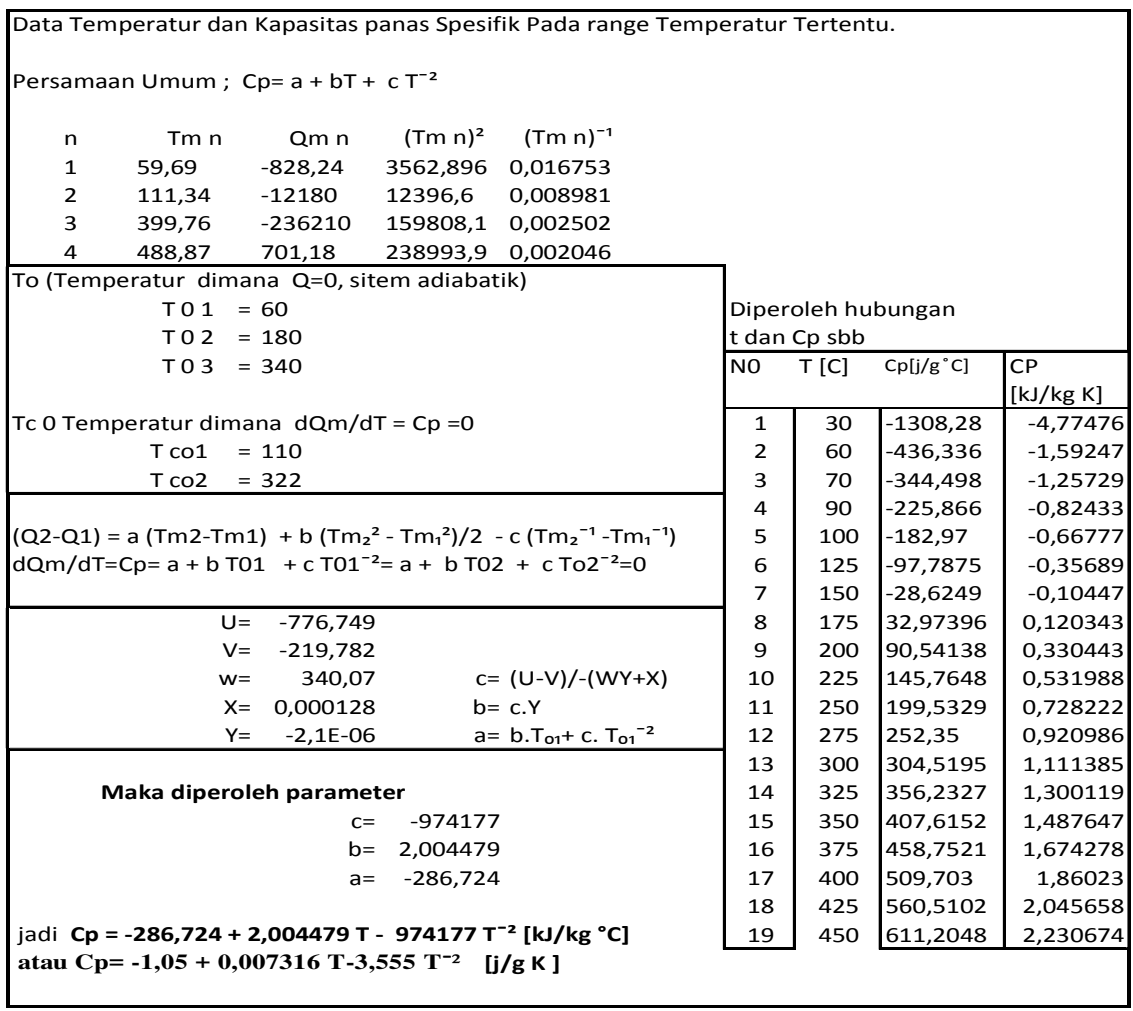

\section{ANALYSIS}

- Coins made of nickel copper alloys protected with aluminum ring onside, is a material to prevent the corrosion process occurs in nickel copper alloys, and to prevent the effects of coin hardness on the user. Aluminum oxide hardness levels are lower than nickel copper alloys

- Coins 1000 IDR have elements $\mathrm{Cu}$ and $\mathrm{Ni}$ form alloy Cn0.9Ni0.1 has FCC crystal structure, 3. Thermal characteristics of coins, among others, at room temperature has a heat capacity $\mathrm{Cp}=1.59$ (joule $/ \mathrm{g} \mathrm{K}$ ), so that it tends to hold heat energy.

- From the SEM data seen are some qualitative elements that the material used as a coin ring having elements with uniform figures, while in the brass parts has a number of elements with the figure berragam, which means that the material is made more than one of the following types with impurities.

- The hardness of the average $84 \mathrm{hv}$ coin brass is a fairly safe hardness so the coin is not easily scratched or peyok, while the ring has a hardness of $72 \mathrm{HV}$ which means softer, so it has a less sharp edge coin edge.

- Coin brass material with copper dominance, contributes to the hardness of the material, while the nickel element will protect the coin brass alloy material from the rust properties, thus coins can be expected to be strong and durable.

\section{CONCLUSIONS}

We have tested the characterization of 1000 USD coin metal, as an alloy material (Alloy), which has a mass density of 7.4, with a mean hardness level. Coins are made of aluminum rings that serve to improve safety for the user, but also for the prevention of corrosion in nickel copper alloys. In addition to having dimensions larger than the general size of the coin, but the total mass of nickel copper alloys can be further saved. Therefore, 1000 USD coins are qualitatively a safe 
convention transaction tool, since it meets the requirements for the security of the user and the coin itself, it is easy and safe to store for a long time. Weaknesses that may be viewed from the price of coin production 1000 IDR is more expensive when compared to coins made of alloys with dominance Aluminum.

\section{ADVICE}

The practice of material characterization is the characterization of the characterization course, so that the students are able to understand the theory. Although practical, this practice requires comprehensive scientific collaboration and high skills. Therefore, it is necessary to socialize the understanding of Standard Operating Procedures on every use of instruments in the Materials Laboratory

\section{REFERENCES}

1. Charles Kittel, Introduction to Solid State Physics, $7^{\text {th }}$ edition, John Wiley \& Sons, New York, 1996.

2. Lawrence H. Van Vlack, Materials Science for Engineers, World Student Series Edition, Addison-Wesley Publishing Company, Reading Massachusetts 1973

3. Peter A. Thrower, Materials in Today World, $2^{\text {nd }}$ edition, The McGraw-Hill Companies, Inc., New York 1996.

4. D.A. Porter, K.E. Easterling., Phase Transformation in Metals and Alloys., Chapman \& Hall, London 1980.

5. A.K. Jena, M.C. Chaturvedi,. Phase Transformation in Materials. Prentice Hall, Englewod Cliffs, New Jersey 1992.

6. C.Suryanarayana, M.Grant Norton,.X-Ray Diffraction A Practical Approach.,Plenum Press, Newyork, London, 1998.'

7. Cao.X, Mohammed. A, Gordon S.H. DSC Study of biodegradable poly (latic acid) poly (hydroxy ester eter) blends., Elseveir, Thermo chemical Acta (2003),115-124, April 2003.

8. C. L. Chiu, Chih-Wei Yu et al.,, Analysis of a Filling Copper Pillar Based on a Thermal Hole Glass Substrate for a Led Chip, International Journal of Electrical and Electronics Engineering Research (IJEEER), Volume 6, Issue 1, January - February 2016, pp. 13-20

9. Wikipedia, the fre eencyclopedia, Differential scanning calorimetry, https://en.wikipedia.org/wiki/Differential_scanning_calorimetry. 